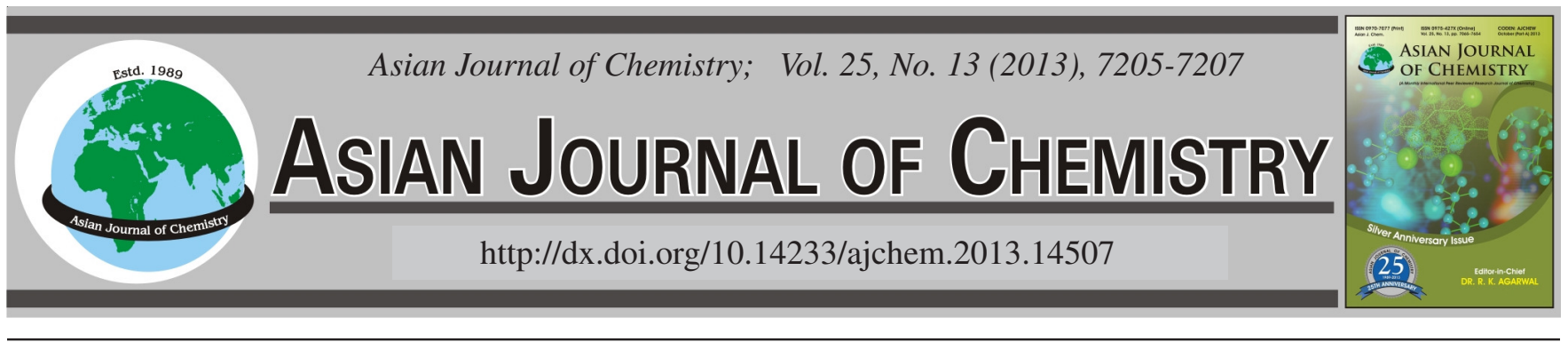

\title{
Effect of Hydrochloric Acid on Formation of Nanocrystalline Bismuth Phosphate Synthesized via Hot Injection Method
}

\author{
S.L. LEE* S.W. Yong and K.O. HARTINI
}

Ibnu Sina Institute for Fundamental Science Studies, Universiti Teknologi Malaysia, 81310 Skudai, Johor, Malaysia

*Corresponding author: Fax: +607 5536080; Tel: +607 5536039; E-mail: sllee@ibnusina.utm.my

(Received: 1 September 2012;

Accepted: 19 June 2013)

AJC-13673

\begin{abstract}
An attempt was made to synthesize nanocrystalline bismuth phosphate via hot injection method. The effect of hydrochloric acid concentration used during the synthesis process was investigated. The acid acted as oxidizing agent in producing $\mathrm{PH}_{3}$, the phosphorus source which reacted with bismuth acetate in 1-octadecene solvent. The XRD patterns showed the materials crystallined in cubic phase when $2 \mathrm{M}$ or $4 \mathrm{M} \mathrm{HCl}$ were used. Meanwhile, a minor impurity phase of $\mathrm{BiOCl}$ was detected when higher concentration of $6 \mathrm{M}$ or $8 \mathrm{M} \mathrm{HCl}$ was applied. It has been demonstrated that the particle size of these single phase materials ranged 5-7 nm. Interestingly, different particle shapes were observed in the bismuth phosphate materials that were prepared using varied concentration of $\mathrm{HCl}$ during synthesis process via hot injection method.
\end{abstract}

Key Words: Nanocrystalline, Bismuth phosphate, Hot injection method.

\section{INTRODUCTION}

Bismuth-based materials have been widely investigated for their various applications such as catalyst, ionic conductor, ion sensor, humidity sensor and separating radioactive elements, etc $^{1-6}$. Of interest bismuth phosphate materials were synthesized previously via solid state reaction, hydrothermal synthesis and ball milling ${ }^{4,7}$. However, the solid state reaction and hydrothermal synthesis required high temperature and long synthesis duration of 2-10 days, leading to a costly production process. Meanwhile, impurities of zirconia were always detected in ball milling prepared samples. In addition, the resulted materials were in micro size when the synthesis methods mentioned above were applied ${ }^{7}$.

In the last decade, more afford were made to synthesize nano materials since they may offer anomalous and interesting properties such as large surface area which could be important for improved performance as catalysts and ionic conductors ${ }^{4,8}$. Recently, good quality and homogenized nanocrystals of indium phosphide (InP) and cadmium selenite $(\mathrm{CdS})$ were successfully prepared via hot injection method ${ }^{9-12}$. Accordingly, this method required shorter duration and lower reaction temperature compared to the others. Besides, this method was relatively simple as it was based on the nucleation and growth of the nanocrystals in hot amphiphile solution soon after the injection of precursor source. Nevertheless, the feasibility of synthesizing nanocrystalline bismuth phosphate materials via this method is unknown. Besides, effect of acid used in the synthesis process is remained unclear. Therefore, in this research, we took the challenge to synthesize nanocrystalline bismuth phosphate material via hot injection method. The effect of $\mathrm{HCl}$ used in synthesis process on formation of nanocrystalline bismuth phosphate was reported.

\section{EXPERIMENTAL}

All the materials were synthesized via hot injection method as described at elsewhere with minor modification 9 . Firstly, mixture of 1-octadecene (Aldrich, $90 \%$ ) and myristic acid (Sigma, $99 \%$ ) was heated at $60{ }^{\circ} \mathrm{C}$ until a homogeneous and clear solution was formed. Then, sufficient amount of bismuth triacetate (Aldrich, $99.99 \%$ ) was added into the solution. The mixture was reheated up to $190^{\circ} \mathrm{C}$. On the other hand, $\mathrm{HCl}$ was injected to $\mathrm{Ca}_{3} \mathrm{P}_{2}$ in order to produce $\mathrm{PH}_{3}$ that was flown and reacted with the bismuth contained mixture. Then, the mixture was left overnight, followed by process of filtration and washing with cold ethanol. Finally, the product was dried in oven at $100{ }^{\circ} \mathrm{C}$ for 2 days. In order to investigate effect of $\mathrm{HCl}$ on formation of nanocrystalline bismuth phosphate, different concentrations (2-10M) of $\mathrm{HCl}$ were injected during the synthesis process.

The phase and crystallinity of the synthesized materials were examined using powder X-ray diffraction employing a Siemens D5000. A scan rate of $0.05^{\circ}$ was applied to record pattern in $2 \theta$ range of $10-90^{\circ}$. The images of the products were captured by the JEOL-JSM-6701F field emitting scanning 
electron which was equipped with EDX software. The transmission electron microscopy images were taken using a JEOLJEM-2100. The microscope was operated at an accelerating voltage of $200 \mathrm{kV}$.

\section{RESULTS AND DISCUSSION}

All the dried samples appeared as fine and shining powder. Figs. 1 and 2 show the XRD patterns of the synthesized materials via hot injection method by using different concentrations of $\mathrm{HCl}$. Results showed that XRD patterns of the materials prepared using $2 \mathrm{M}$ and $4 \mathrm{M} \mathrm{HCl}$ were well matching with that of reported $\mathrm{Bi}_{3.69} \mathrm{P}_{\mathrm{O} .31} \mathrm{O}_{6.31}$ (PDF file number 43-0455) which was prepared by melting mixtures of $\mathrm{Bi}_{2} \mathrm{O}_{3}$ and $\left(\mathrm{NH}_{4}\right)_{2} \mathrm{HPO}_{4}$ at $1000{ }^{\circ} \mathrm{C}$ for $2 \mathrm{~min}$ and quenching in ice water. The reported material crystallined in cubic Fm $3 \mathrm{~m}$ phase with $\mathrm{A}=5.4716 \AA$. On the other hand, it had also been demonstrated that a mixed phase material consisted of $\mathrm{Bi}_{7} \mathrm{PO}_{13}$ and sillenite phase was obtained in material with $\mathrm{Bi}: \mathrm{P}$ composition of $12: 1$ after solid state reaction at $800^{\circ} \mathrm{C}$ for 2 days ${ }^{7}$. Obviously, our current finding indicates that a single phase bismuth phosphate material in cubic phase could be produced at lower temperature of $190{ }^{\circ} \mathrm{C}$, even though the crystallinity of the resulted material was considerably low.

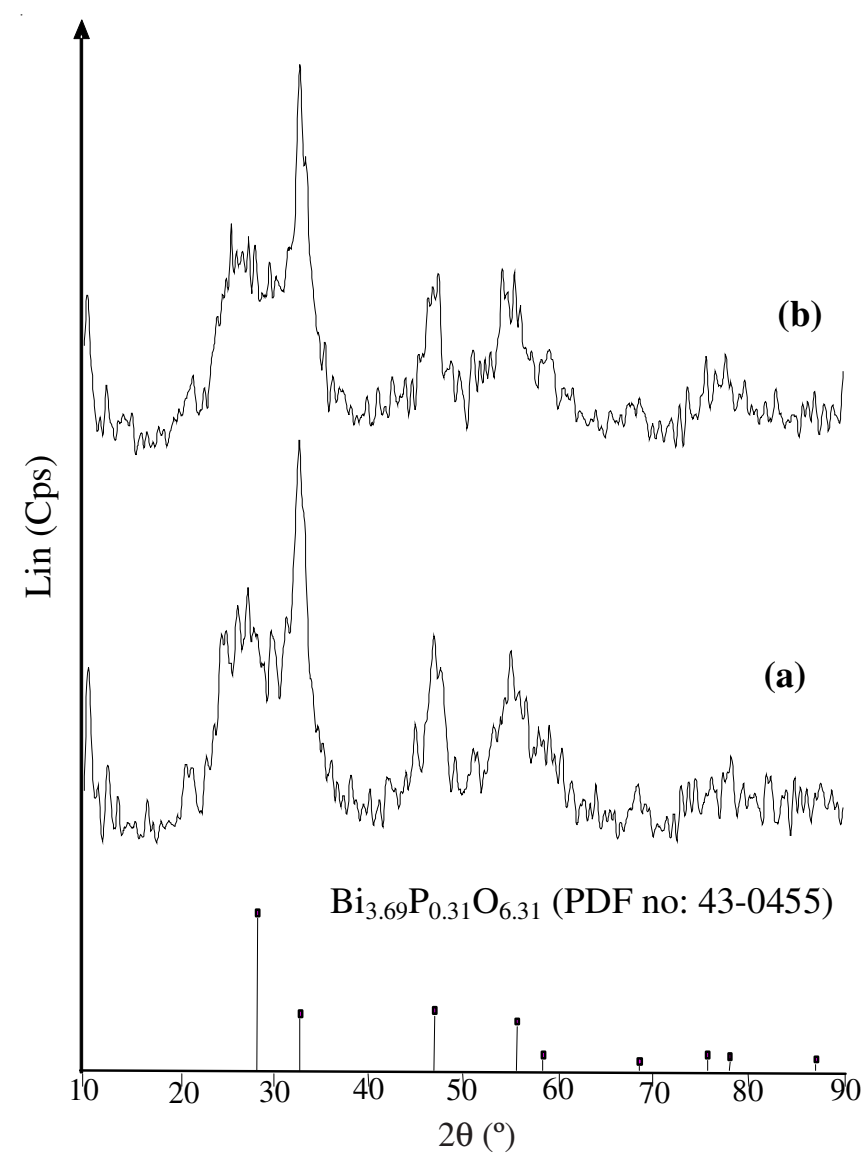

Fig. 1. XRD patterns of single phase bismuth phosphate prepared using (a) $2 \mathrm{M} \mathrm{HCl}$; (b) $4 \mathrm{M} \mathrm{HCl}$

Meanwhile, a tetragonal phase of $\mathrm{BiOCl}$ present as impurity when $6 \mathrm{M}$ or $8 \mathrm{M} \mathrm{HCl}$ was used (Fig. 2). The phenomena implies the preference of bismuth precursor to react with the excess $\mathrm{HCl}$ rather than $\mathrm{PH}_{3}$, resulting in formation of
$\mathrm{BiOCl}$. Apparently, a single phase material of $\mathrm{BiOCl}$ was detected in $10 \mathrm{M} \mathrm{HCl}$ prepared material. It is note-worthy that the crystallinity of the materials increased with increasing of concentration of $\mathrm{HCl}$ used in preparation procedure.

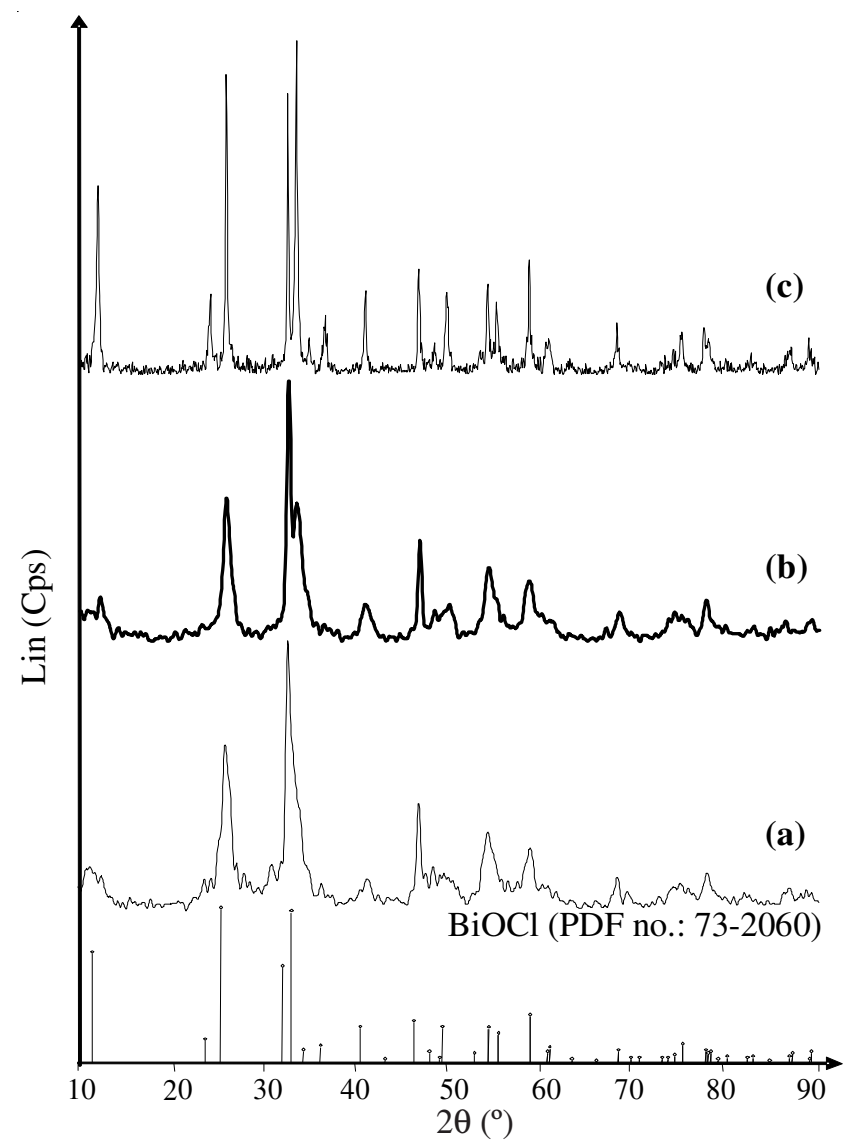

Fig. 2. XRD patterns of samples prepared using (a) $6 \mathrm{M} \mathrm{HCl}$; (b) $8 \mathrm{M} \mathrm{HCl}$; (c) $10 \mathrm{M} \mathrm{HCl}$

FESEM micrographs of the synthesized bismuth phosphate materials are shown in Fig. 3. The surface morphology of these materials was homogenized and their particles were in spherical shape. It could be seen that the particles distribution of these materials was in bulky scale. For the mixed-phase materials prepared using $6 \mathrm{M}$ and $8 \mathrm{M} \mathrm{HCl}$, their particles were flowerlike in shape. Meanwhile, $\mathrm{BiOCl}$ produced using $10 \mathrm{M} \mathrm{HCl}$ was inhomogeneous with the various particle shapes were observed. The observation strongly suggested concentration of $\mathrm{HCl}$ affected surface morphology of the materials formed.
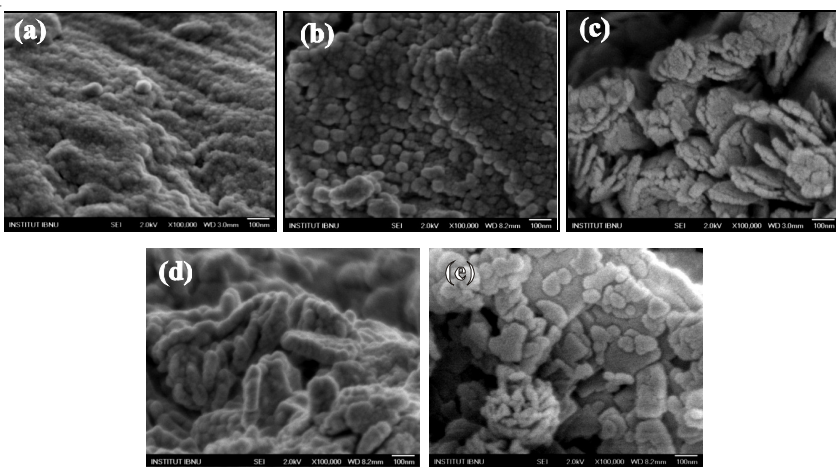

Fig. 3. FESEM micrographs of materials prepared using (a) $2 \mathrm{M} \mathrm{HCl}$; (b) $4 \mathrm{M} \mathrm{HCl}$; (c) $6 \mathrm{M} \mathrm{HCl}$; (d) $8 \mathrm{M} \mathrm{HCl}$; and (e) $10 \mathrm{M} \mathrm{HC}$ 
TEM images of the dispersed single phase bismuth phosphate materials were shown in Fig. 4. These materials were indentified with mean diameters of 5 to $7 \mathrm{~nm}$, indicating nanocrystalline bismuth phosphate materials were successfully synthesized via hot injection method. The synthesized materials using $2 \mathrm{M}$ and $4 \mathrm{M} \mathrm{HCl}$ were fine and off-white in colour. Meanwhile, beige powder was obtained when 6-10 M HCl was used in synthesis process. In fact, the bismuth phosphate materials that were synthesized via high temperature solid state reaction and ball milling method were yellow in colour ${ }^{7}$. The discrepancies could be attributed to the formation of nanoparticles through hot injection method.
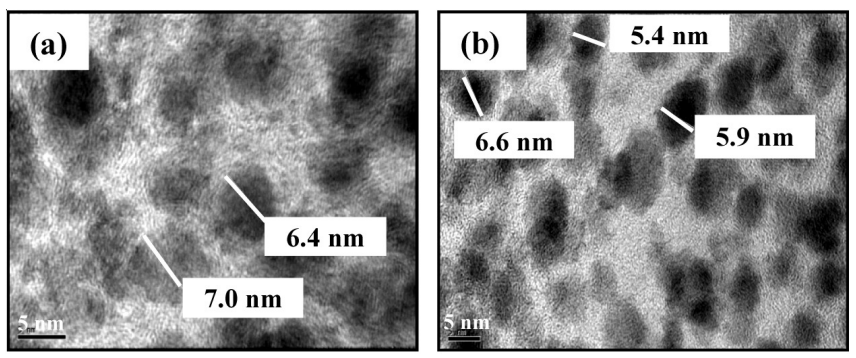

Fig. 4. TEM images of bismuth phosphate materials synthesized using (a) $2 \mathrm{M} \mathrm{HCl}$ and (b) $4 \mathrm{M} \mathrm{HCl}$

On the other hand, elemental analysis using EDX revealed the ratios of $\mathrm{Bi}$ to $\mathrm{P}$ in the materials prepared were 9.7:1 and 10.5:1 using $2 \mathrm{M}$ and $4 \mathrm{M} \mathrm{HCl}$, respectively (Table-1). The results were in good agreement with that of suggested in pattern matching in XRD analysis where $\mathrm{Bi}: \mathrm{P}=11.9: 1$. However, further confirmation is needed for elemental composition determination by using other instrumental analysis such as ICP-MS. Besides, presence of both $\mathrm{P}$ and $\mathrm{Cl}$ was detected in $6 \mathrm{M}$ and $8 \mathrm{M}$ prepared materials, implying co-existence of bismuth phosphate and $\mathrm{BiOCl}$ as shown in the XRD results. Meanwhile, $\mathrm{P}$ was not found in $10 \mathrm{M} \mathrm{HCl}$ prepared material, strongly supporting our previous statement that claimed the formation of $\mathrm{BiOCl}$. The decrease in $\mathrm{P}$ content with arising of $\mathrm{HCl}$ concentration indicates the lesser competency of $\mathrm{PH}_{3}$ compared to $\mathrm{HCl}$ in the reaction with $\mathrm{Bi}$ precursor.

\begin{tabular}{cccccc}
\multicolumn{7}{c}{ TABLE-1 } \\
\multicolumn{7}{c}{$\begin{array}{c}\text { ELEMENTAL ANALYSIS OF BISMUTH PHOSPHATE } \\
\text { MATERIALS PREPARED USING DIFFERENT } \\
\text { CONCENTRATIONS OF HCl }\end{array}$} \\
\hline$[\mathrm{HCl}]$ & $\mathrm{Bi}$ & $\mathrm{P}$ & $\mathrm{O}$ & $\mathrm{Cl}$ & $\mathrm{Bi}: \mathrm{P}$ \\
$/ \mathrm{M}$ & $($ mass \%) & $($ mass \%) & $($ mass \%) & (mass \%) & ratio \\
\hline 2 & 96.64 & 1.48 & 1.88 & - & $9.7: 1$ \\
4 & 96.07 & 1.36 & 2.57 & - & $10.5: 1$ \\
6 & 92.64 & 1.23 & 2.14 & 3.96 & - \\
8 & 90.81 & 0.96 & 2.20 & 6.03 & - \\
10 & 87.74 & - & 2.41 & 9.85 & - \\
\hline
\end{tabular}

\section{Conclusion}

Nanocrystalline bismuth phosphate materials have been synthesized via hot injection method. A single-phase material which crystallined in cubic phase was obtained in $2 \mathrm{M}$ or $4 \mathrm{M}$ $\mathrm{HCl}$ prepared materials. Particle size of these materials ranged 5-7 nm. Variation of particle shapes were observed when different concentrations of $\mathrm{HCl}$ were used.

\section{ACKNOWLEDGEMENTS}

One of the authors (S.L. Lee) thank Ministry of Higher Education Malaysia for the research grant through Fundamental Research Grant Scheme (Research vote: 78334) and Universiti Teknologi Malaysia for the Research University Grant (Research vote: Q.J. 13000.2526.00H08) and other research facilities.

\section{REFERENCES}

1. C.K. Lee and C.S. Ong, Solid State Ionics, 117, 301 (1999).

2. W.L. Liu, J. Mater. Sci., 40, 1827 (2005).

3. L. Dimesso, G. Gnappi and A. Montenero, J. Mater. Sci., 26, 4215 (1991).

4. F. Xue, H. Li, Y. Zhu, S. Xiong, X. Zhang, T. Wang, X. Liang and Y. Qian, J. Solid State Chem., 182, 1396 (2009).

5. M. Sheng, L. Gu, R. Kontic, Y. Zhou, K. Zheng, G. Chen, X. Mo and G.R. Patzke, Sens. Actuators B, 166-167, 642 (2012).

6. G.J. Lumetta, J.C. Braley, J.M. Peterson, S.A. Bryan and T.G. Levitskaia, Environ. Sci. Technol., 46, 6190 (2012).

7. L. Wang, J. Tang and H. Yin, Asian J. Chem., 25, 2146 (2013).

8. Q.N. Pham, C. Bohnke, M.P. Lopez and O. Bohnke, Chem. Mater, 18, 4385 (2006).

9. L. Li, M. Protière and P. Reiss, Chem. Mater, 20, 2621 (2008).

10. L.J. Zhang, X.C. Shen, H. Liang, S. Guo and Z.H. Liang, J. Colloid Interf. Sci., 342, 236 (2009).

11. P.K. Jain, B.J. Beberwyck, L.K. Fong, M.J. Polking and A.P. Alivisatos, Angew. Chem., 124, 2437 (2012).

12. C. Banerjee, D.L. Hughes, M. Bochmann and T. Nann, J. Chem. Soc., Dalton Trans., 41, 7244 (2012). 